\title{
Sistema de avaliação de cidades de referência em transportes e mobilidade urbana sustentável
}

\author{
Assessment system of cities that are reference \\ in transport and sustainable urban mobility
}

Vinicius Tischer [l] Marcus Polette [II]

\begin{abstract}
Resumo
Diversas externalidades resultantes de um modelo inadequado de planejamento de transportes urbanos afetam diretamente a qualidade ambiental e de vida da população. Nesse sentido, este trabalho tem por objetivo analisar cidades de referência em mobilidade urbana sustentável, avaliando-as por meio de indicadores, determinados pelos sistemas de avaliação de cidades: Mercer, Copenhagenize, Walk Score, UITP Index e European Green Capital. Foram selecionadas as cidades mais bem classificadas para validar indicadores relacionados a infraestrutura e gestão de transportes e mobilidade urbana. Os resultados demonstraram quais as práticas exitosas essas cidades referência têm adotado para a melhoria da mobilidade urbana, qualidade ambiental urbana e qualidade de vida da população, servindo de orientação para o planejamento urbano para as cidades brasileiras.
\end{abstract}

Palavras-chave: cidades; planejamento urbano; mobilidade urbana sustentável; transportes; sistema de avaliação de cidades.

\begin{abstract}
Several externalities resulting from an inadequate model of urban transport planning directly affect the environmental and living quality of the population. In this sense, the purpose of this study is to analyze cities of reference in sustainable urban mobility, evaluating them through indicators determined through city assessment systems: Mercer, Copenhagenize, Walk Score, UITP Index and European Green Capital. The best ranked cities were selected to validate indicators related to transportation infrastructure and management and urban mobility. The results demonstrated the successful practices these reference cities have adopted to improve urban mobility, urban environmental quality and the quality of life of the population, serving as an urban planning guide for Brazilian cities.
\end{abstract}

Keywords: cities; urban planning; sustainable urban mobility; transport; city assessment system. 


\section{Introdução}

A melhoria das condições da mobilidade urbana representa um dos maiores desafios das cidades atualmente em todo o mundo. Se, por um lado, a maioria das cidades enfrenta problemas graves relacionados a deficiência dos serviços e conflitos ambientais e econômicos, por outro, existem cidades que estão superado esses problemas, com resultados positivos, meIhorando a qualidade de vida da população e reduzindo impactos negativos de ações previamente implementadas.

As escolhas convencionais de planejamento urbano acumuladas geralmente resultam em problemas urbanos crônicos, e, com isso, as cidades modernas buscam políticas para sustentar sua mobilidade urbana, reduzindo as externalidades de modelo de transportes fundamentado no uso de automóveis individuais. Muitos estudos recorrem a técnicas de benchmarking buscando práticas exitosas de determinadas temáticas para que sejam feitas comparações por meio de valores de referência ou para a utilização ou adaptação de metodologias para a área de interesse.

Para Miranda e Silva (2012), encontrar cidades para servir como referência (benchmarks) representa possibilidade de aprender sobre as estratégias aplicadas para alcançar um bom desempenho na maioria dos indicadores, podendo sugerir que a cidade oferece condições justas e equitativas de mobilidade para todos os seus cidadãos.

Essas cidades tornaram-se referência pela validação de experiências bem-sucedidas na resolução de conflitos urbanos e na redução das externalidades do sistema de transportes e mobilidade urbana, apreendendo a lidar com desafios que as posicionam em destaque em diversos índices de avaliação, como é o caso, por exemplo, das cidades europeias de Amsterdã e Copenhague, com infraestrutura e deslocamentos cicloviário muito expressivos (Pucher e Buehler, 2008), e das cidades alemães, referências na adoção de modos ferroviários (Renner e Gardner, 2010). Na América do Norte, há iniciativas bem-sucedidas de redução da dependência do uso de veículos particulares, com destaque para Portland, Nova York e Vancouver (Sadik-Khan, 2017). Na América Latina, algumas experiências também são tidas como referência, principalmente pela adequação à situação socioeconômica local, com destaque para Bogotá (Colômbia) e Curitiba (Brasil) com experiências bem-sucedidas, especificamente sobre o transporte coletivo (Montgomery, 2017 e Lindau et al., 2013).

Há um desafio, no entanto, de determinar os indicadores que serão avaliados e quais as cidades que podem servir de referência para o estudo das ações implementadas. Atualmente, há diversos sistemas de avaliação que buscam classificar, de maneira hierárquica, quais cidades conseguem destacar-se em função de diversos parâmetros de avaliação.

Meijering, Kern e Tobi (2014) e Carr et al. (2010) complementam que sistemas de avaliação de cidades podem contribuir para o desenvolvimento de políticas ambientais. 0 uso de indicadores é fundamental para o entendimento desse processo; para entender se sistemas de transporte estão, de fato, tornando-se mais ou menos sustentáveis e se as políticas de transporte estão ajudando a atingir as metas. Assim, a mensuração de desempenho do planejamento para transporte e meio ambiente faz-se necessária (Gudmundsson, 2000). 
Segundo Hammond et al. (2005), o uso de indicadores é fundamental como medida que fornece uma referência para uma questão de maior significância ou torna perceptível uma tendência ou fenômeno que não é imediatamente detectável. 0 significado de um indicador estende-se, além do que é realmente medido, a um fenômeno maior de interesse. Estes fornecem informações de uma forma mais simples e mais facilmente compreensível do que as estatísticas, por vezes complexas, ou outros tipos de dados, porque implicam um modelo ou um conjunto de pressupostos que relaciona 0 indicador a fenômenos mais complexos.

No entanto, devem ser conhecidas suas limitações, para que suas premissas de uso não causem falhas de interpretação nos resultados. Kozaryn (2013) cita, por exemplo, que usualmente são avaliados parâmetros objetivos, como a infraestrutura; fatores que nem sempre captam a percepção das pessoas da qualidade de vida vivenciada na cidade.

Há a existência de diversos índices pertinentes, nacionais e internacionais, que integram diversas métricas da temática para a composição de rankings de atendimento desses parâmetros, o que permite averiguar quais cidades possuem melhores condições em determinado parâmetro de avaliação.

Ocorre que há uma necessidade de investigação no final do ciclo, acerca da aplicação desses sistemas de avaliação, para que seja possível identificar sua aplicação, permitindo o entendimento do porquê essas cidades mais bem graduadas nessas escalas se tornaram referência. Para que assim, através das medidas praticadas, sejam compreendidas quais ações estruturantes e não estruturantes contribuem para a melhoria da qualidade de vida da população e minimizam os impactos ambientais.

Para tal, este trabalho tem por objetivo analisar indicadores de transportes e mobilidade urbana sustentável em cidades de referência. Utilizaram-se indicadores obtidos em sistemas de avaliação que classificam cidades com base no seu desempenho em diversos aspectos: qualidade de vida, mobilidade urbana, qualidade ambiental. Como estudo de caso, os indicadores foram validados para as cidades bem-colocadas nesses sistemas de avaliação, selecionadas em todos os continentes, considerando cidades de pequeno, médio e grande porte.

Dessa forma, os resultados pretendidos da pesquisa foram a identificação de características comuns dessas cidades que permitem estabelecer relações acerca de melhores práticas passíveis de serem empregadas em cidades brasileiras, visando a atender às necessidades de mobilidade e acessibilidade da população, compatibilizadas com a mitigação de custos sociais, ambientais e econômicos do atual modelo empregado atualmente em municípios brasileiros.

As áreas urbanas no Brasil possuem uma importância determinante no contexto nacional. Cerca de 174 milhões de pessoas habitam a área urbana no Brasil (84,7\%, segundo 0 IBGE, 2016), sendo $33 \%$ da população residente em cidades de porte médio (100 mil - 1 milhão) e outros $21 \%$ em cidades com mais de 1 milhão de habitantes (IBGE, 2010). Especialmente em cidades de médio e grande porte, os problemas de mobilidade urbana são mais evidentes - com níveis excessivos de poluição, ruído, congestionamentos, acidentes que afetam diretamente o bem-estar social e a qualidade 
ambiental urbana - e prejudicam a competitividade e dinamismo econômico das cidades (Andrade et al., 2017; Dey, Caulfield e Ghosh, 2018; Rubin e Leitão, 2013).

Nota-se que, mesmo a partir de avanços como a Política Nacional da Mobilidade Urbana (PNMU, promulgada em 2012, com orientação de ações voltadas para o transporte ativo), o País ainda necessita de medidas mais efetivas e duradouras de melhoria do transporte público coletivo e de ações estruturais de melhoria das condições para transportes ativos. Citam-se, ainda, problemas de crescimento desorientado das cidades e dispersão urbana que afetam o acesso da população e que potencializam os desafios de mobilidade urbana, sobretudo no atendimento dos anseios da população, que deseja melhoria da eficiência nos deslocamentos, segurança, qualidade, conforto e custo compatível (NTU, 2017; CNM, 2016).

Com isso, este trabalho fornecerá uma avaliação das condições de sistema de transportes e mobilidade urbana por meio de indicadores obtidos em cidades com os melhores indicadores de mobilidade e sustentabilidade em nível mundial. Além disso, compreender quais as ações adotadas por essas cidades, por meio das respostas dos indicadores avaliados, permite conceber e estabelecer metas e objetivos que as cidades devem buscar para melhorar sua condição de mobilidade e, consequentemente, a qualidade ambiental e de vida da população.

A identificação de padrões de referência é fundamental para a gestão da mobilidade urbana, haja vista que muito municípios implementam ações equivocadas que supostamente serão melhores para a cidade, porém, acabam na contramão de tendências mundiais e das melhores práticas adotadas, mesmo não tendo a situação financeira como o maior limitante. Uma comparação dos indicadores e práticas de cidades de referência pode subsidiar essas tomadas de decisões, ampliando a discussão e as estratégias de resolução de conflitos urbanos e consequentemente, obtendo um desenvolvimento urbano resiliente e fundamentado em práticas testadas e reconhecidas.

Com isso, este trabalho tem a intenção de contribuir com a avaliação de ações adotadas por cidades, de modo a subsidiar a tomada de decisões com base em ações já implementadas e que conduziram a resultados positivos nas cidades do estudo de caso. A comparação do desempenho das cidades de referência em termos de mobilidade urbana sustentável auxiliará, ainda, a compreender os impactos gerados pelo sistema de transportes e permitirá estabelecer metas e objetivos com base em um benchmarking, ou seja, nas melhores práticas, fornecidas pela comparação dessas cidades bem-conceituadas.

\section{Sistemas de avaliação de cidades}

Inserida no contexto urbano, uma cidade é o resultado de uma interação complexa de condições socioeconômicas, geográficas, culturais, que são parcialmente determinadas localmente. Mas, ao mesmo tempo, a posição de uma cidade é fortemente influenciada por seus esforços estratégicos resultantes da governança urbana (Giffinger e Gudrun, 2010).

A comparação e a classificação das cidades podem ser um instrumento importante 
para identificar as vantagens comparativas. Rankings revelam pontos fortes e fracos específicos das cidades, subsidiando a definição de ações específicas ao considerar os resultados de uma classificação ou benchmarking de alta qualidade (ibid.).

Segundo Meijering, Kern e Tob. (2014) e Schönert (2003), os sistemas de avaliação de cidades podem contribuir para a avaliação e o desenvolvimento da política urbana, auxiliando a desencadear um processo de discussão sobre estratégias de desenvolvimento regional, além de estimular as cidades a aprenderem umas com as outras.

Portugal (2017) aponta que novas abordagens do planejamento de transporte que incorporem parâmetros de sustentabilidade em sua concepção estão sendo buscadas. Com isso, indicadores de avaliação de cidades passam a ter importância fundamental para aferição de parâmetros que contribuem, de fato, para a redução de impactos ambientais e melhoria das condições de mobilidade urbana e das condições sociais relacionados ao meio urbano.

Atualmente há uma série de sistemas de avaliação que se utiliza de indicadores para a avaliação de fatores, como qualidade de vida, mobilidade urbana sustentável, mobilidade de pedestres e de ciclistas. Podemos citar os seguintes sistemas: Mercer, European Green Capital Award (EGCA), UITP, WalkScore e Copenhagenize, descritos a seguir:

- Bicycle Friendly Cities (Copenhagenize Index)-Iniciativa da organização Copenhagenize Designe Company para avaliar as cidades com as melhores práticas de uso da bicicleta inserida no ambiente urbano. São consideradas treze categorias de avaliação que incluem aspectos da infraestrutura, perfil do usuário, segurança, cultura da bicicleta, evolução, políticas públicas de incentivo (CDC, 2017).

- Walk Score - Índice aplicado nos Estados Unidos, Canadá e Austrália, que classifica cidades e bairros nesses países. 0 Walk Score mede o grau de caminhabilidade de qualquer endereço, com base no tráfego, no acesso ao transporte público e na qualidade das condições para os ciclistas. A pontuação é concebida com base na distância em cada categoria. Uma função de decaimento é usada para dar pontos aos fatores mais distantes. 0 Walk Score também utiliza análise da densidade populacional e métricas das vias, quadras, densidade de cruzamentos, usando como fonte de dados - Google, Education.com, Open Street Map, o Censo dos EUA, Localeze e locais adicionados pela comunidade de usuários do Walk Score (Walk Score, 2017). Duncan et al. (2011) confirmam, em seu estudo, que a generalização de descobertas anteriores demonstra que 0 Walk Score é uma medida válida para estimar a capacidade de locomoção em vizinhanças em múltiplas localizações geográficas e em múltiplas escalas espaciais.

- Urban Mobility Index (International Association of Public Transport, UITP) - Índice criado para avaliar o desempenho da mobilidade urbana em cidades em todo o mundo. Atualmente analisa 84 cidades, avaliando 19 critérios do grau de implementação (integração e eficiência de transporte público e bicicletas, suporte financeiro, etc.), e de desempenho (poluição atmosférica, acidentes, tempo de deslocamento, etc.) (UITP, 2014).

- Quality of Living Ranking (Mercer) - Este índice avalia a qualidade de condições de vida em mais de 440 cidades, de acordo com 39 indicadores, agrupados em 10 categorias: 
serviços públicos de transporte, estabilidade política e social, economia, cultura, saúde, educação, recreação, consumo de bens, habitação e ambiente natural (Mercer, 2015).

- 0 European Green Capital Award (EGCA) é o resultado de uma iniciativa tomada, inicialmente, por um grupo de cidades europeias e posteriormente lançada pela Comissão Europeia em 2008. Os objetivos do EGCA são recompensar cidades que tenham um histórico consistente de alcançar altos padrões ambientais: incentivar as cidades a comprometerem-se com metas contínuas e ambiciosas para uma maior melhoria ambiental e para o desenvolvimento sustentável; motivar e promover melhores práticas e experiências em todas as outras cidades europeias, para melhorar a qualidade de vida dos seus cidadãos e reduzir o seu impacto no ambiente global. A seleção das cidades é avaliada com base em 12 indicadores: mudanças climáticas: mitigação e adaptação; mobilidade urbana sustentável; uso sustentável do solo; natureza e biodiversidade; qualidade do ar; ruído; resíduos sólidos; água; crescimento e inovação ecológica; desempenho energético; e governança (EC, 2017).

Esses sistemas de avaliação são conhecidos e largamente utilizados por cidades em nível mundial. Apesar de possuírem limitações inerentes de indicadores, suas avaliações são positivas e funcionam como recomendações acerca da importância do uso e para a avaliação de desempenho de determinados de cidades e processos urbanos, como demonstram os estudos sobre EGCA (Meijering, Kern e Tobi, 2014), UITP (Moeinaddini et al., 2015), Walk Score (Carr et al., 2010 e Duncan et al., 2011), Copenhagenize (Zayed, 2016) e Mercer (Morais et al., 2013 e Llacuna et al., 2014).
Tais sistemas de avaliação consideram um total de 57 critérios em suas abordagens (Quadro 1), considerando diversos eixos temáticos que variam de acordo com o escopo de cada índice. No entanto, observa-se que indicadores de mobilidade urbana são comuns em todos os sistemas, inclusive para os que têm a proposta de avaliar o nível de qualidade de vida e de qualidade ambiental urbana.

\section{Materiais e métodos}

Esta pesquisa consiste na avaliação de ações de mobilidade urbana, por meio de indicadores, considerando cidades de estudo de caso com as melhores classificações em sistemas de avaliação, visando entender como cada cidade realiza o seu planejamento e medidas relacionadas a mobilidade urbana, tornando-se referência pelos sistemas de avaliações estudados. A seleção dos sistemas de avaliação (citados no Quadro 1) partiu de necessidade de selecionar qual a escala das ações implementadas, relacionadas aos transportes e mobilidade urbana, seria desejável para exercer influência na qualidade de vida da população e na qualidade ambiental urbana.

Esses sistemas foram elencados pela relevância gerada na pesquisa e foram respaldados por métodos consistentes e por produções de relatórios que subsidiaram a avaliação do desempenho de cidades, considerando aspectos que relacionavam o desempenho ambiental e da infraestrutura implementada com o desenvolvimento humano, a qualidade de vida e a qualidade ambiental de cidades. Ressalta-se, ainda, que, além de avaliar cidades, esses sistemas geram processos de proatividade dos 


\section{Quadro 1 - Sistemas de avaliação e indicadores associados}

\begin{tabular}{|c|c|}
\hline \multicolumn{2}{|c|}{ Indicadores componentes dos sistemas de avaliação } \\
\hline \multicolumn{2}{|c|}{ Urban Mobility Index (UITP) } \\
\hline $\begin{array}{l}\text { - Participação dos modos (emissão zero) na divisão de modos } \\
\text { de transportes } \\
\text { - Participação dos transportes públicos na divisão de modos de } \\
\text { transportes } \\
\text { - Aumento do compartilhamento de transporte público na } \\
\text { divisão modal } \\
\text { - Densidade de estradas } \\
\text { - Densidade da rede cicloviária } \\
\text { - Densidade demográfica } \\
\text { - Distribuição de cartão inteligente } \\
\text { - Compartilhamento de bicicleta }\end{array}$ & $\begin{array}{l}\text { - Compartilhamento de carro } \\
\text { - Frequência de transporte público } \\
\text { - Atratividade financeira do transporte público } \\
\text { - Iniciativas do setor público } \\
\text { - Emissões de } \mathrm{CO}_{2} \text { relacionadas com os transportes } \\
\text { - Concentração de } \mathrm{NO}_{2} \\
\text { - Concentração de } \mathrm{PM}_{10} \\
\text { - Mortes relacionadas com o trânsito } \\
\text { - Aumento da participação dos modos de emissão zero } \\
\text { - Tempo médio de viagem para trabalhar } \\
\text { - Veículos registrados }\end{array}$ \\
\hline \multicolumn{2}{|c|}{ Copenhagenize Index } \\
\hline $\begin{array}{l}\text { - Apoio público ao uso de bicicletas } \\
\text { - Cultura de bicicleta } \\
\text { - Instalações para bicicleta } \\
\text { - Infraestrutura cicloviária } \\
\text { - Programa de compartilhamento de bicicletas } \\
\text { - Divisão de uso de bicicletas por sexo } \\
\text { - Participação das bicicletas nos modos de transportes }\end{array}$ & $\begin{array}{l}\text { - Aumento de participação do modo bicicleta } \\
\text { - Percepção de segurança } \\
\text { - Políticas públicas } \\
\text { - Aceitação social } \\
\text { - Planejamento urbano } \\
\text { - Traffic Calming } \\
\text { - Bicicletas de carga e logística }\end{array}$ \\
\hline \multicolumn{2}{|c|}{ European Green Capital Award (EGCA) } \\
\hline $\begin{array}{l}\text { - Mudança climática: mitigação } \\
\text { - Mudança climática: adaptação } \\
\text { - Mobilidade Urbana Sustentável } \\
\text { - Uso sustentável da terra } \\
\text { - Natureza e biodiversidade } \\
\text { - Qualidade do ar }\end{array}$ & $\begin{array}{l}\text { - Ruído } \\
\text { - Resíduos sólidos } \\
\text { - Água } \\
\text { - Crescimento verde e eco-inovação } \\
\text { - Desempenho energético } \\
\text { - Governança }\end{array}$ \\
\hline \multicolumn{2}{|c|}{ Quality of Living Ranking (Mercer) } \\
\hline $\begin{array}{l}\text { - Bens de consumo } \\
\text { - Ambiente econômico } \\
\text { - Habitação } \\
\text { - Considerações médicas e de saúde } \\
\text { - Ambiente natural }\end{array}$ & $\begin{array}{l}\text { - Ambiente político e social } \\
\text { - Serviços públicos e transportes } \\
\text { - Lazer } \\
\text { - Escolas e educação } \\
\text { - Ambiente sociocultural }\end{array}$ \\
\hline \multicolumn{2}{|c|}{ Walk Score } \\
\hline - Distância entre residências e serviços & - Distância entre residências e transporte público \\
\hline
\end{tabular}

Fonte: Adaptado de UITP, Copenhagenize, EGCA, Mercer e Walk Score.

governos das cidades participantes no sentido de melhoria da infraestrutura, em função dos resultados das avaliações, e orientam políticas públicas e a difusão de informações para a sociedade civil.
Após a averiguação de quais indicadores compunham cada sistema de avaliação (Quadro 1), agruparam-se os específicos relacionados aos transportes e mobilidade urbana de cada sistema. Os indicadores escolhidos foram 
validados em cidades selecionadas em cada um dos sistemas de avaliação, sendo realizada pesquisa para obter as informações dos indicadores em cada cidade em estudo de caso. Assim, foi realizada avaliação dos indicadores, comparando valores entre as cidades e, por fim, desempenhada análise sobre as ações, estruturais e não estruturais, comuns entre as cidades, e sobre como estas podem auxiliar na melhoria da mobilidade urbana das cidades brasileiras em acordo com o fluxograma apresentado pela Figura 1.
Seleção e classificação dos temas e indicadores relacionados a mobilidade urbana

Cada um dos sistemas de avaliação selecionados possui diversas temáticas de abrangência, como apresentado pelo Quadro 1. Como o objetivo é trabalhar com o setor de transporte e mobilidade urbana, foi realizada triagem em cada um dos sistemas para que se buscassem os indicadores ou áreas temáticas relacionadas a esse aspecto.

Figura 1 - Fluxograma de desenvolvimento da pesquisa



Fonte: os autores. 
Esses indicadores evidenciados, em cada um desses sistemas, serão validados para cidades bem graduadas nesses sistemas de avaliação. Portanto, a partir dessa seleção, os indicadores foram organizados de modo a permitirem orientar a coleta de dados para estabelecer um panorama das ações e característica das cidades analisadas.

\section{Seleção de cidades dos sistemas de avaliação para validação dos indicadores}

A seleção das cidades para validar os indicadores ocorreu considerando-se as melhores colocadas nos sistemas de avaliação, com cidades de diversos portes populacionais, evitando-se, no entanto, grandes metrópoles, com objetivo de que estas pudessem indicar a adoção de medidas efetivas previamente à ocorrência de problemas crônicos do sistema de transportes, que muitas vezes são irreversíveis ou de elevados custos de mitigação em cidades de grande porte. Cabe destacar que a seleção de cidades não foi rígida, uma vez que todas as cidades bem colocadas possuíam iniciativas positivas e ações relevantes à melhoria da qualidade do sistema de transportes.

\section{Pesquisa dos parâmetros para as cidades}

A pesquisa dos indicadores ocorreu considerando-se, prioritariamente, dados oficiais governamentais dos municípios, censos nacionais, pesquisas e relatórios técnicos produzidos pelos municípios. Também foi necessário realizar pesquisas em artigos científicos, relatórios de organizações não governamentais e, esporadicamente, em notícias relacionadas ao assunto.

Devido ao fato de cada país e/ou cidade ter seu procedimento de geração e disponibilização de dados, nem sempre os resultados foram obtidos no mesmo ano. Também foram elencadas as informações-chave que permitiam compreender a essência das ações ou resultados obtidos pelas cidades, não entrando em detalhes, uma vez que algumas cidades possuem informações disponíveis mais detaIhadas que outras.

\section{Comparação e avaliação das ações de transportes mobilidade urbana nas cidades}

A compilação dos dados foi realizada em planilha, contendo todos os indicadores e o valor correspondente às cidades avaliadas. Essa planilha sintetiza, por temas de afinidade, 0 resultado numérico ou qualitativo de cada indicador, permitindo realizar comparação entre as cidades, além de identificar qual a magnitude das ações de transportes e mobilidade urbana em cada cidade, podendo inferir para ações relacionadas ao benchmarking de medidas de eficiência em transportes e mobilidade urbana sustentável.

A avaliação realizada considerou, assim, os indicadores quantitativos e qualitativos. No primeiro caso, foi realizada a criação de taxas ponderadas per capita, por área, ou percentagem. Isso permitiu, ainda, extrair referências estatísticas, como média, máximos e mínimos e desvio padrão, o que subsidia a análise das comparações e conclusões. 
É ainda importante considerar que a avaliação dos indicadores qualitativos permitiu identificar explicação da operacionalização de determinado tema e, em alguns itens, expressou uma lista de ações desenvolvidas em favor do critério estudado. Dessa forma, não menos importante, permite assimilações da importância de determinadas ações para a eficiência na mobilidade urbana.

\section{Resultados}

Os resultados serão apresentados em cinco etapas. A primeira refere-se ao resultado da seleção de indicadores e temas relacionados à mobilidade urbana, que serão utilizados para validar as informações para as cidades de estudo de caso. Na segunda etapa, serão apresentadas as cidades selecionadas como estudo de caso. Na terceira etapa, serão apresentados os resultados dos indicadores validados para cada cidade de estudo de caso demonstrando a comparação entre elas. Na quarta etapa, esses indicadores apresentados serão discutidos considerando-se os aspectos relevantes e estatísticos dos dados obtidos. A última etapa dos resultados tratará dos indicadores qualitativos, discutindo as medidas de controle institucionais de planejamento urbano.

\section{Seleção e classificação dos indicadores e temas}

Os sistemas de avaliações de cidades selecionados, Copenhagenize, Walkscore, UITP Index, Mercer e EGCA, possuem temas relacionados, porém, com objetivos gerais distintos, desenvolvidos respectivamente para: infraestrutura cicloviária, de pedestres, mobilidade urbana, qualidade de vida e qualidade ambiental urbana.

Todos os sistemas de avaliação consideram o sistema de transportes e mobilidade urbana em sua avaliação enquanto temática fundamental para que se entenda o desempenho das cidades, considerando cada um dos objetivos propostos por esses sistemas de avaliação (vide Quadro 2).

0 cruzamento dos componentes dos diferentes sistemas de avaliação permitiu reunir temas em comum entre eles, sendo possível classificá-los em dois grupos principais. 0 primeiro trata de temas/indicadores relacionados diretamente com os transportes e impactos relacionados; e o segundo caracteriza-se como indicadores suplementares que relacionam aspectos do planejamento urbano, demografia, aspectos institucionais que contribuem para a melhoria da mobilidade urbana.

Dessa forma, os indicadores relacionados a mobilidade urbana pelos sistemas de avaliação exprimem mensurações relacionadas a: infraestrutura cicloviária e para pedestre, design urbano, emissões, acidentes de transportes, tempo de deslocamento e congestionamentos, transporte público, ruído e consumo de combustível (Quadro 2).

Esses parâmetros foram enquadrados em dois aspectos principais: infraestrutura urbana e de transportes e impactos ambientais e socioeconômicos (Quadro 3). A primeira classe refere-se às infraestruturas de transporte público, cicloviária, para pedestres e o planejamento urbano (design urbano). A segunda está relacionada aos impactos decorrentes 
do sistema de transportes e mobilidade urbano, especificamente ruído, poluição do ar, consumo de combustível, acidentes e tempo de deslocamento ou em congestionamento.

\section{Quadro 2 - Sistemas de avaliação de parâmetros que envolvem mobilidade urbana sustentável}

\begin{tabular}{|l|l|}
\hline \multicolumn{1}{|c|}{ Índice } & \multicolumn{1}{c|}{ Parâmetros relacionados a mobilidade urbana } \\
\hline Copenhagenize & Infraestrutura cicloviária \\
\hline Walk score & Infraestrutura para pedestres, design urbano \\
\hline UITP Index & Emissões, infraestrutura cicloviária, design urbano, acidentes, tempo de deslocamento \\
\hline Mercer Quality of life & Emissões, congestionamento/tempo perdido, transporte público \\
\hline European Green Capital Award & Emissões, ruído, transporte público, consumo de combustível \\
\hline
\end{tabular}

Fonte: os autores.

\section{Quadro 3 - Classificação dos indicadores e temas associados aos sistemas de avaliação estudados}

\begin{tabular}{|l|l|}
\hline \multicolumn{1}{|c|}{ Aspecto } & \multicolumn{1}{c|}{ Temas relacionados } \\
\hline Infraestrutura urbana e de transportes & $\begin{array}{l}\text { Infraestrutura cicloviária } \\
\text { Infraestrutura para pedestre } \\
\text { Design urbano } \\
\text { Transporte público }\end{array}$ \\
\hline Impactos ambientais e socioeconômicos & $\begin{array}{l}\text { Ruído } \\
\text { Consumo de combustível } \\
\text { Emissões } \\
\text { Acidentes } \\
\text { Tempo de deslocamento/congestionamentos }\end{array}$ \\
\hline Indicadores suplementar & Institucional \\
\hline
\end{tabular}

Fonte: os autores. 


\section{Seleção de cidades para o estudo de caso}

As cidades mais bem-classificadas nos sistemas de avaliação: UITP Mobility Index, Mercer Quality of Living City, Copenhagenize Index, Walk Score e European Green Capital (EGCA) são apresentadas na Tabela 1. Essas cidades possuem indicadores elevados de desempenho em diversos critérios de avaliação, tornando-as referência e válidas para o estudo de caso da pesquisa.

Com relação ao índice do UITP Mobility Index, foram selecionadas as cidades de Portland (EUA), Curitiba (Brasil) e Santiago (Chile). Foram incluídas as cidades Santiago e Curitiba por serem as representantes da América do Sul e Brasil mais bem-classificadas no sistema de avaliação UITP Mobility Index. Singapura também foi incluída por ser a melhor

Tabela 1 - Caracterização das cidades selecionadas para o estudo de caso

\begin{tabular}{|c|c|c|c|c|c|}
\hline Sistema de avaliação & $\begin{array}{c}\text { Copenhagenize, } \\
\text { UITP }\end{array}$ & Copenhagenize & Copenhagenize & $\begin{array}{c}\text { Mercer, ITP, ECGA, } \\
\text { Copenhagenize }\end{array}$ & Mercer \\
\hline Cidade & Amsterdam & Utrecht & Strasbourg & Copenhagen & Düsseldorf \\
\hline País & Holanda & Holanda & França & Dinamarca & Alemanha \\
\hline População & 779.808 & 311.367 & 271.782 & 562.379 & 598.686 \\
\hline Área $\left(\mathrm{km}^{2}\right)$ & 219 & 99,21 & 78,26 & 88,25 & 217 \\
\hline Densidade (hab./km²) & $3.560,80$ & $3.138,50$ & $3.472,80$ & $6.372,60$ & $2.759,00$ \\
\hline Turistas/ano & 15.854 .000 & 4.528 .000 & 8.400 .000 & 11.000 .000 & $4.403 .960,00$ \\
\hline IDH do país/ordem no & & & & & \\
\hline ranking mundial ${ }^{1}$ & $0,931 / 10$ & $0,931 / 10$ & $0,901 / 24$ & $0,929 / 11$ & $0,936 / 5$ \\
\hline Sistema de avaliação & Mercer & Walk Score & UITP, Mercer & UITP & UITP \\
\hline Cidade & Vancouver & Minneapolis & Singapura & Helsinki & Portland \\
\hline País & Canada & EUA & Singapura & Finlândia & EUA \\
\hline População & 631.486 & 413.651 & 5.610 .000 & 599.676 & 609.456 \\
\hline Área $\left(\mathrm{km}^{2}\right)$ & 114,97 & 148,85 & 791,1 & 184,5 & 375,78 \\
\hline Densidade (hab./km²) & $5.492,60$ & $2.687,70$ & $7.091,40$ & $3.250,30$ & $1.621,80$ \\
\hline Turistas/ano & 10.000 .000 & 30.900 .000 & 16.402 .593 & 3.576 .804 & 8.990 .000 \\
\hline IDH do país/ordem no & & & & & \\
\hline ranking mundial & $0,926 / 12$ & $0,924 / 13$ & $0,932 / 9$ & $0,920 / 15$ & $0,924 / 13$ \\
\hline Sistema de avaliação & UITP & UITP & ECGA & ECGA & ECGA \\
\hline Cidade & Santiago & Curitiba & Essen & Umeå & Liubliana \\
\hline País & Chile & Brasil & Alemanha & Suécia & Eslovênia \\
\hline População & 6.763 .000 & 1.752 .000 & 571.000 & 118.000 & 283.000 \\
\hline Área $\left(\mathrm{km}^{2}\right)$ & 641,4 & 430,9 & 210,3 & 34,15 & 115 \\
\hline Densidade (hab./km²) & $10.544,10$ & $4.065,90$ & $2.715,00$ & $3.455,00$ & $2.460,00$ \\
\hline Turistas/ano & 5.640 .700 & 3.720 .000 & 1.300 .000 & 900.000 & 1.000 .072 \\
\hline IDH do país/ordem no & & & & & \\
\hline ranking mundial & $0,843 / 44$ & $0,759 / 79$ & $0,936 / 5$ & $0,933 / 7$ & $0,896 / 25$ \\
\hline
\end{tabular}

(1) Ano de referência: 2018. Disponível em: http://hdr.undp.org/en/2018-update. Acesso em: 3 abr 2019.

Fonte: os autores. 
cidade asiática representada nas avaliações da UITP e Mercer, além de possuir experiências pioneiras na gestão de tráfego urbano. Estas, ainda, são as únicas cidades estudadas com mais de um milhão de habitantes (Tabela 1).

Nas avaliações do sistema Mercer, as cidades bem-classificadas são Copenhague (Dinamarca), Vancouver (Canadá), Singapura e Düsseldorf (Alemanha). No Copenhagenize Index, as cidades selecionadas com alta classificação foram Copenhague, Amsterdã (Holanda), Utrecht (Holanda), Estrasburgo (França). Para o Walk Score, selecionaram-se as cidades de Vancouver e Minneapolis; e, para o EGCA, foram selecionadas as finalistas dos últimos anos: Liubliana (Eslovênia), Essen (Alemanha) e Umeå (Suécia).

É notável destacar que muitas cidades são reincidentes em mais de um sistema de avaliação, com experiências que as posicionam na vanguarda de ações de sustentabilidade e mobilidade urbana em nível mundial. A exemplo, a cidade mais citada é Copenhague, posicionada em quatros rankings, além de Amsterdã, Vancouver e Singapura presentes em dois.

Ressalta-se que a natureza de seleção das cidades implica a existência de disparidades socioeconômicas que devem ser consideradas na interpretação dos resultados, assim como pesadas em caso de adaptação à realidade brasileira. Entre os países presentes na análise, possivelmente o Brasil possua os maiores desafios diante de sua complexidade de fatores políticos-institucionais e territoriais que, ignoradas, podem tornar projetos inexequíveis ou, mesmo que executados, não solucionar determinada demanda.

Nota-se, entretanto, que todas as cidades de estudo de caso possuem iniciativas relevantes para os contextos socioeconômicos de mobilidade urbana no país e mesmo internacional. Dessa forma, os indicadores devem ser avaliados não apenas isoladamente, mas comparando-se valores em comum entre os países, sobretudo os de elevado IDH, permitindo inferir sobre a importância de quais parâmetros são determinantes e prioritários para orientar suas políticas urbanas. E, assim, orientar reflexões sobre a pertinência dessas políticas aplicadas à realidade.

\section{Comparação entre as cidades}

A comparação entre as cidades, realizada com base nos indicadores obtidos dos sistemas de avaliação, permitiu estabelecer correlações entre mais de uma variável.

As cidades com as maiores taxas de deslocamentos realizados por bicicletas são Copenhague e Amsterdã, com mais de $50 \%$ dos deslocamentos urbanos realizados por bicicleta. Destacam-se, ainda, as cidades de Umeå e Utrecht, com $26 \%$ e $27 \%$ dos deslocamentos, respectivamente (Figura 2).

As altas taxas de uso cicloviário também estão associadas à infraestrutura implementada. Essas cidades possuem elevadas taxas de cobertura por sistema cicloviário, com destaque para a Helsinque que atinge $1200 \mathrm{~km}$ de sistema cicloviário. No geral, as demais cidades possuem um sistema cicloviário entre 200-500km. Observa-se, ainda, relação entre a infraestrutura existente $\left(\mathrm{km}\right.$ ou $\left.\mathrm{km} / \mathrm{km}^{2}\right)$ com a maior quantidade de infraestrutura por habitante. As cidades com maiores índices de infraestrutura por habitante são Umeå, Helsinque e Estrasburgo (Figura 3). 
Figura 2 - Viagens realizadas por bicicleta



*Dados não disponíveis para Curitiba. Fonte: os autores.

Figura 3 - Indicadores de infraestrutura cicloviária

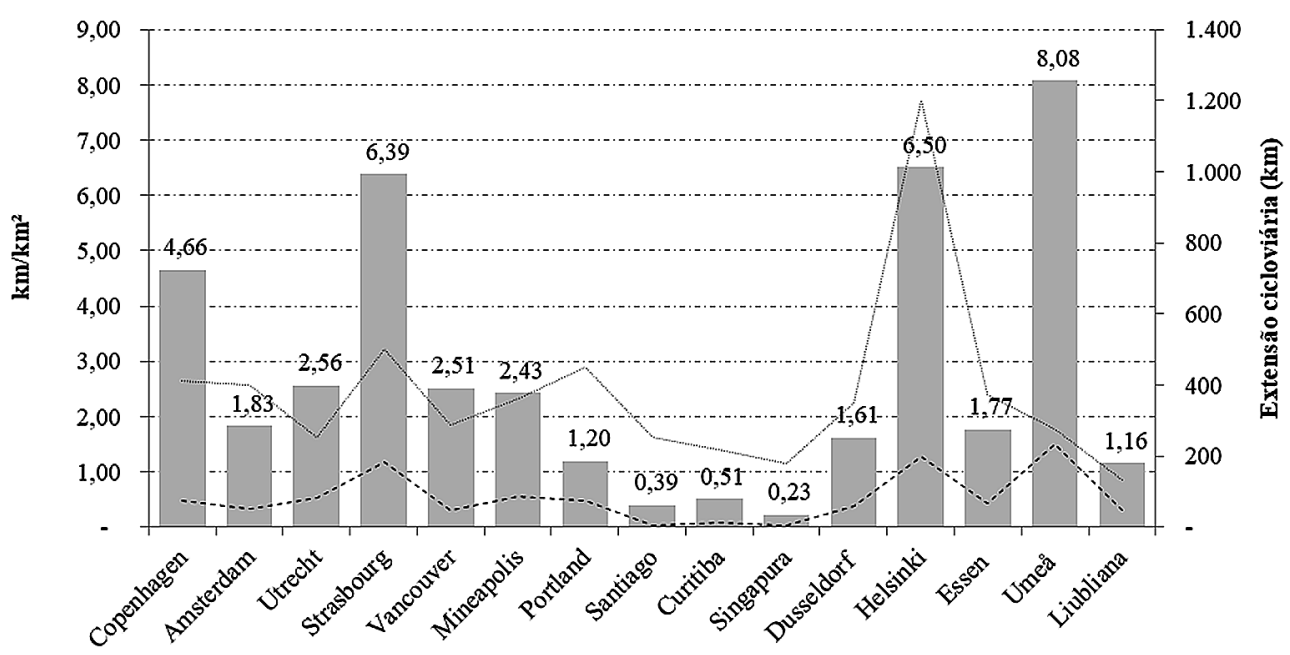

\footnotetext{
$\square$ Densidade cicloviária $\left(\mathrm{km} / \mathrm{km}^{2}\right) \quad$-...-...- Extensão ci cloviária $(\mathrm{km}) \quad$-..- Densidade per capita $(\mathrm{km} / 100 \mathrm{mil} \mathrm{hab})$
}

Fonte: os autores. 
Em contraste com a presença de infraestrutura e viagens realizadas por meio de bicicletas, observam-se taxas inversamente proporcionais de acidentes. Mesmo com boas iniciativas na promoção de transportes ativos, as cidades americanas estudadas possuem as maiores taxas de acidentes resultante em óbitos, tanto de pedestres como de ciclistas; modos mais vulneráveis no sistema de mobilidade urbano, com destaque para Curitiba e Santiago (1,4 e 1,2 óbitos/100mil habitantes, respectivamente), com taxas muito superiores à média (Figura 4). Destaca-se que as cidades com as maiores taxas de deslocamentos por bicicletas possuem, no geral, as menores taxas de acidentes com fatalidades, com destaque para Copenhague e Amsterdã, que possuem mais de
$50 \%$ dos deslocamentos feitos por bicicletas. Umeå e Helsinque, por exemplo, possuem anos sem ocorrências de acidentes fatais.

Com relação à infraestrutura para pedestre, foi identificado que todas as cidades buscam alternativas para fomentar a circulação de pedestres na cidade, e muitas adotam a restrição de circulação de veículos em ruas centrais, para que sejam aumentadas as taxas de circulação de pedestres, além de fomentar a economia e melhorar a estética da cidade (Figura 5).

Destacam-se as cidades de Helsinque, Copenhague e Estrasburgo, com as maiores áreas de vias peatonais, com valores superiores a $1 \mathrm{~m}^{2}$ de área por habitante, estando em Helsinque a maior infraestrutura identificada,

Figura 4 - Acidentes de transportes.

Vítimas fatais de ciclistas por 100mil habitantes

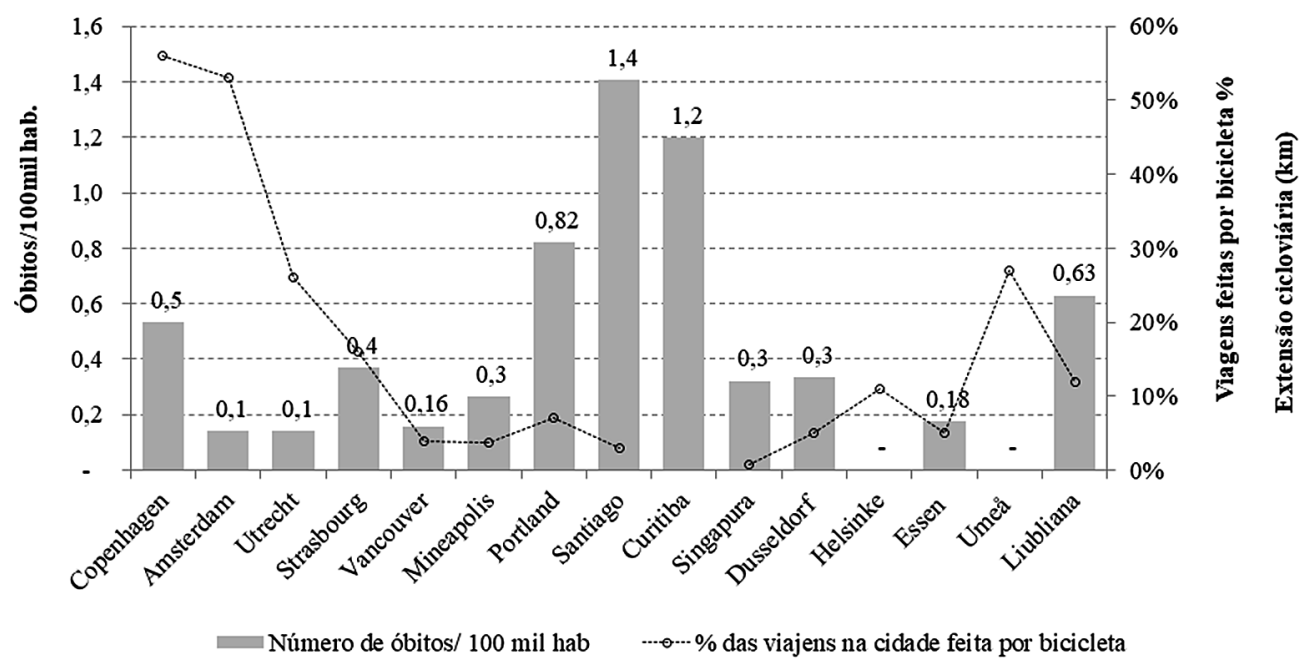

Fonte: os autores. 
Figura 5 - Ruas de uso exclusivo para pedestres

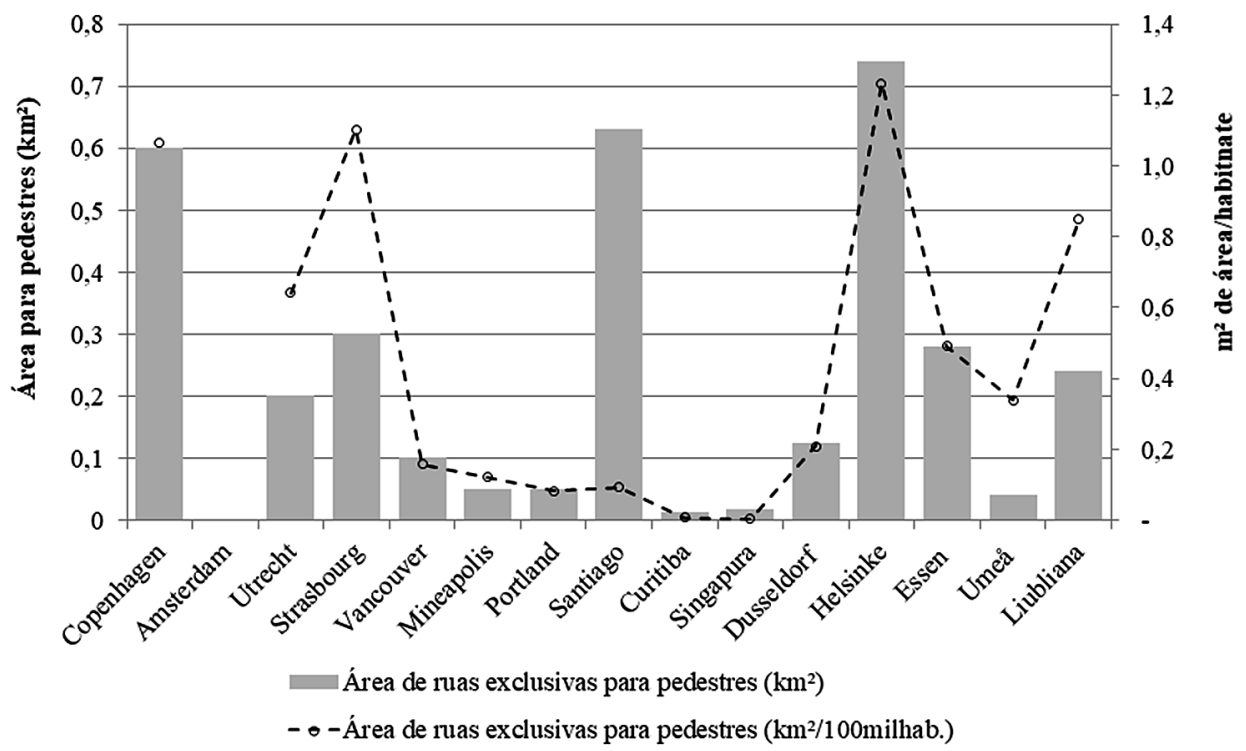

*Informações não localizadas para Amsterdam.

Fonte: os autores.

com cerca de $0,72 \mathrm{~km}^{2}$ em área peatonal. $\mathrm{Na}$ cidade de Santiago, mesmo possuindo uma quantidade expressiva de área peatonal, esse efeito é minimizado quando relativizado com o tamanho da população ou com a área da cidade, tendo em vista ela ser uma cidade de grande porte.

Com relação aos acidentes envolvendo pedestres, as cidades analisadas com as maiores taxas são Curitiba e Santiago (5,4 e 2,7 óbitos por $100 \mathrm{mil} /$ habitantes, respectivamente), com destaque para a cidade brasileira, que possui taxa duas vezes maiores do que a segunda colocada (Figura 6). Destaca-se, ainda, um predomínio de menores taxas de acidentes em cidades europeias (taxas abaixo de 0,9 óbitos/100mil habitantes), sendo verificado menor dependência do uso de carros e maiores taxas de uso de transporte ativo.
Iniciativas importantes, como o compartilhamento de veículos, também foram verificadas. Com relação ao compartilhamento de bicicletas, as cidades com o sistema mais estruturado são Estrasburgo, com 1.619 bicicleta/100mil habitantes, seguido de Essen, com 525 bicicletas/100mil habitantes. Utrecht, apesar de ser umas das cidades com melhores condições se infraestrutura para ciclistas, ainda não possui sistema implementado, estando em fase de estudo. Com relação ao compartilhamento de carros, a cidade de Vancouver atinge os maiores valores, com cerca de 238 carros/100mil habitantes, seguido de Portland (175) e Amsterdã (167) (Figura 7).

Com relação à frota de veículos, observa-se uma predominância de mais carros registrados per capita nas cidades americanas de Portland e Minneapolis, com valores acima 
Figura 6 - Acidentes de transportes. Vítimas fatais e viagens de pedestres

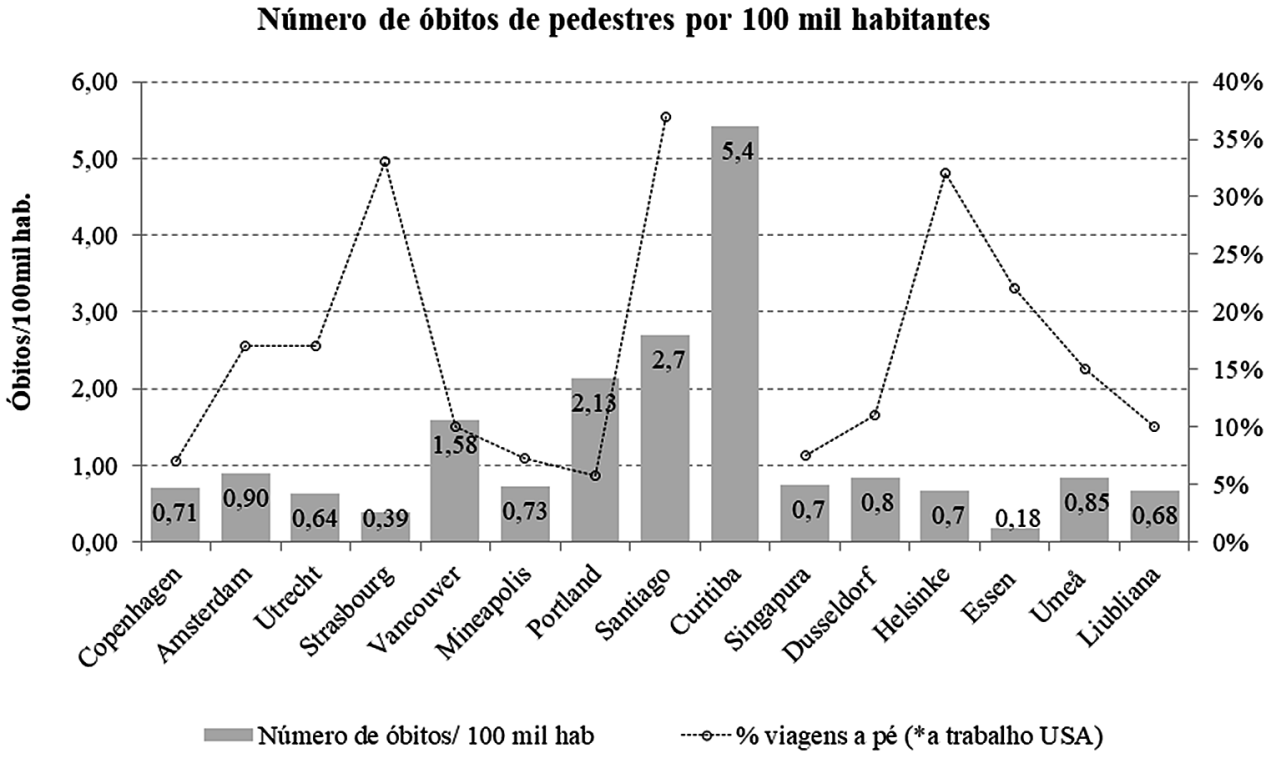

Fonte: os autores

Figura 7 - Número de carros e bicicletas compartilhados

N. habitantes por bicicleta compartilhada



Carros compartilhados por 100 hab.

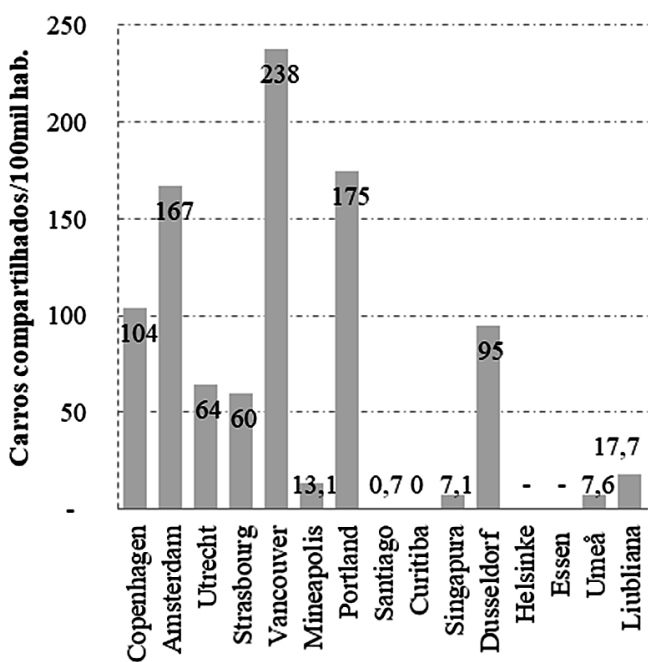

* Existe mas sem dados disponíveis para Düsseldorf; ** Existe, mas sem dados disponíveis para Essen. Fonte: os autores. 
de 0,8 carros/habitante. As menores taxas de motorização são observadas em Singapura e Santiago, com menos de 0,2 veículos/habitante (Figura 8).

Com relação ao número de estações, cidades como Copenhague, Amsterdã e Utrecht possuem as maiores taxas de cobertura por habitantes. Ao mesmo tempo, as cidades americanas também possuem iniciativas relevantes, com destaque para Portland e Minneapolis.

Com relação à divisão dos modos de transporte, foram observados altos índices de uso de transporte público nas cidades estudadas, com destaque para Helsinque, Santiago,
Singapura e Düsseldorf, com mais de $30 \%$ dos deslocamentos urbanos realizados por transporte público (ônibus e transporte ferroviário) (Figura 9). 0 transporte ativo nas cidades estudadas também demonstrou elevados valores, atingindo cerca de $90 \%$ nas cidades de Copenhague e Amsterdã (incluindo transporte público, uso de bicicletas e pedestres), sendo citado por Moeinaddini et al. (2015) como um dos fatores fundamentais para ambiente urbano sustentável. As cidades norte-americanas apresentaram as menores taxas (com menos de $30 \%$ em Minneapolis e Portland).

Figura 8 - Frota de veículos registrados

e estações de recarga para carros elétricos

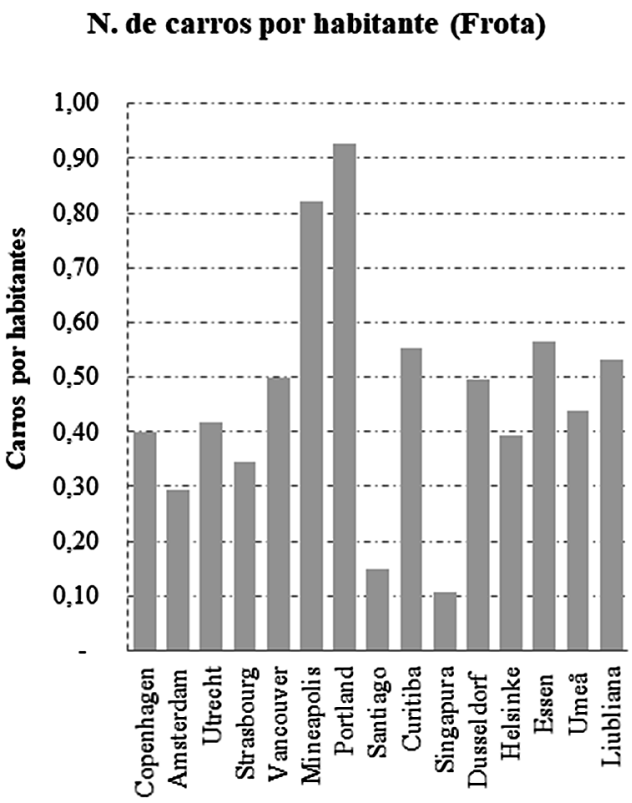

\section{Estações de recarga veículos elétricos por 100 hab.}

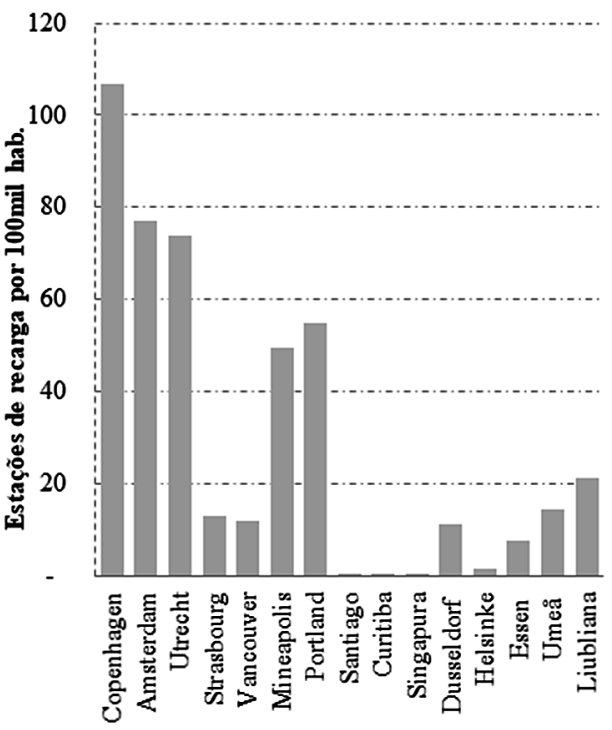

Fonte: os autores. 
Figura 9 - Viagens realizadas por transporte público e transporte ativo
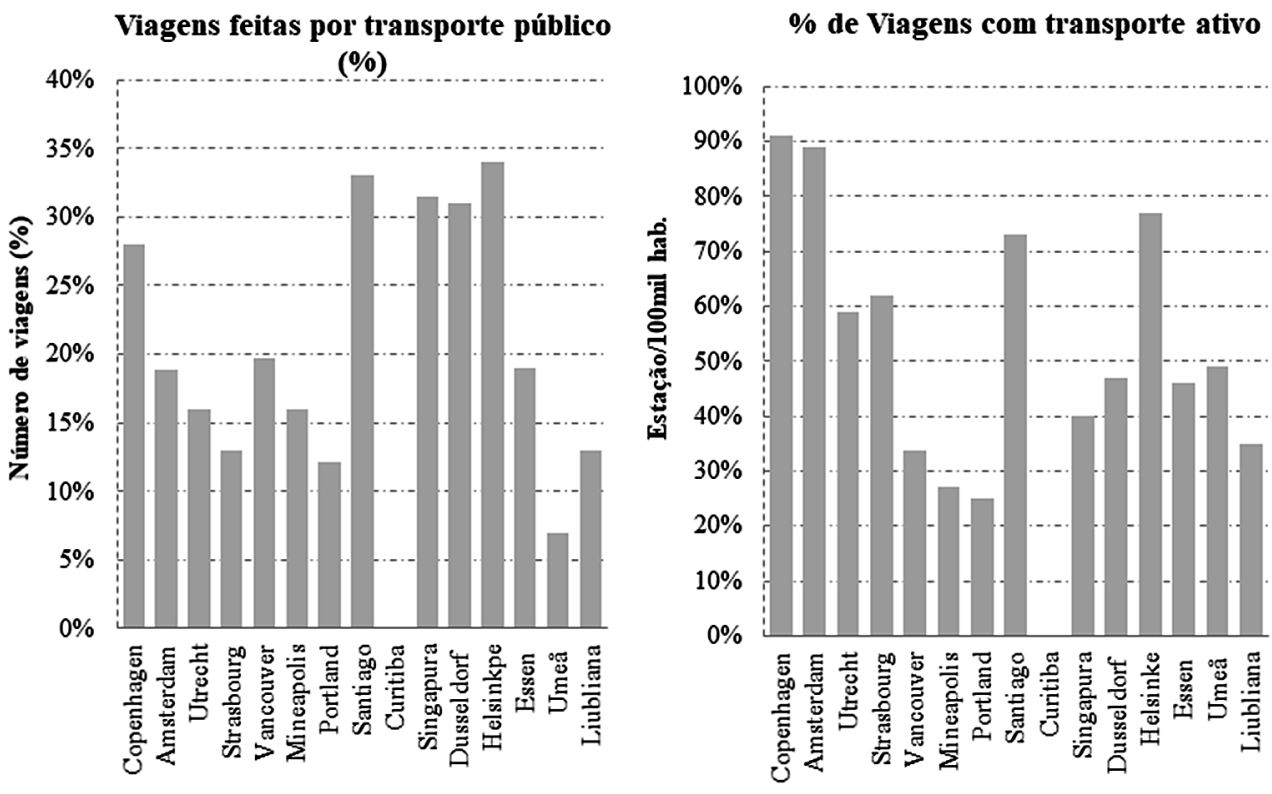

* Dados não disponíveis para Curitiba.

Fonte: os autores.

Análise dos indicadores

Observando os indicadores das cidades avaliadas, a infraestrutura cicloviária mostrou-se como importante parâmetro para cidades com bons índices nos sistemas de avaliação considerados, sendo a extensão média nas cidades avaliadas de cerca de $376 \mathrm{~km}$, mostrando que, em média, 2,8km de ciclovias são implementados em cada $\mathrm{km}^{2}$ de área urbana nas cidades estudadas ou $81,4 \mathrm{~km}$ de ciclovias para cada 100 mil habitantes. Valores máximos, considerando-se a densidade da rede (por área e por habitantes), foram observados em Umeå e valores mínimos foram verificados em Singapura.
Isso contribui para que o número de viagens realizadas por bicicletas aumente consideravelmente, sendo verificada média de $16,4 \%$ das viagens (nas cidades estudadas), são realizadas por bicicleta, atingindo o valor máximo de $56 \%$ (Copenhague). Em contraste, a menor taxa de deslocamento foi observada em Singapura $(0,8 \%$ dos deslocamentos feitos por bicicleta). Para Curitiba, não há dados disponíveis.

A existência de bicicletas de uso compartilhado está presente em uma média de 344,6 bicicletas para cada 100 mil habitantes, com valor máximo de 1.618,9 bicicletas/100mil habitantes, em Estrasburgo. A cidade de Curitiba não possui sistema instalado, e em Utrecht 
um sistema encontra-se em fase de estudo. Não foram localizados dados quantitativos para a cidade de Düsseldorf, apesar de haver sistema implementado.

Outro parâmetro que mostrou sua importância na avaliação da mobilidade urbana sustentável é a presença de infraestrutura ferroviária, mesmo em cidades de pequeno porte (até 200 mil habitantes, segundo a OECD, 2018). Os indicadores apontaram uma média de $93,4 \mathrm{~km}$ de ciclovia nas cidades estudadas ou de 16.138 habitantes para cada km implementado. Além disso, verificam-se altos valores de deslocamento por trens nas cidades, em média 46.115 viagens por 100 mil habitantes. Ressalta-se que, das cidades avaliadas, apenas Curitiba não possui infraestrutura ferroviária.

Com relação ao deslocamento de pedestres, observa-se importante indicador relacionado às vias urbanas de uso exclusivo para pedestres, sendo observada uma média de cerca de $0,37 \mathrm{~km}^{2}$ dessas áreas por cidade. Com relação aos deslocamentos nos diferentes modos de transportes, este demonstrou uma média de cerca de $16,4 \%$.

A infraestrutura de ônibus demonstrou que há, em média, 124,7 ônibus de transporte público para cada 100 mil habitantes. Variando de um número mínimo de 24,9 (Amsterdã) para 237,5 (Vancouver).

Quanto à frota de veículos, observou-se uma média de 0,47 carros para cada habitante, atingindo um máximo de 0,93 (Portland) e um mínimo de 0,11 (Singapura). 0 compartilhamento de carros também mostrou-se relevante nas cidades analisadas, atingindo média de 65 veículos disponíveis para cada 100 mil habitantes. Das cidades avaliadas, Curitiba não possui o serviço implementado.
Outro indicador avaliado é relacionado a veículos elétricos, sendo observada a existência de iniciativas em todas as cidades. Nesse sentido, foi verificada uma média de 26,2 estações de recarga por cidade avaliada, atingindo o máximo de 106,7 estações por 100 mil habitantes em Copenhague e o mínimo de 0,11 em Curitiba, com 2 estações implementadas, e 0,12 em Santiago, com 8 estações implementadas.

Com relação ao uso de transporte ativo, os deslocamentos realizados a pé, por bicicletas e por meio de transporte público representaram uma média de $51,1 \%$ dos deslocamentos no total de diferentes modos de transportes, atingindo valores máximos de $91 \%$ e $89 \%$ em Copenhague e Amsterdã, respectivamente. Os menores valores foram registrados em Portland e Minneapolis, com $24,9 \%$ e $27 \%$, respectivamente.

Avaliando-se o número de acidentes de transportes que resultam em fatalidades, verificou-se uma média de 0,45 óbitos de ciclistas por 100 mil habitantes, com máximo de 1,4 em Santiago (seguido de Curitiba com 1,2 óbitos/100mil habitantes). Algumas cidades, como Umeå e Helsinque, possuem anos sem vítimas fatais de ciclistas. Para pedestres, os números são mais expressivos, sendo verificada uma média de 1,30 óbitos/100mil habitantes, com máximo de 5,42 em Curitiba e mínimo de 0,18 em Essen. Destacam-se, ainda, baixas taxas de óbitos nas cidades como Essen e Umeå, com 1 óbito registrado no ano de referência avaliado.

Quando observada a dimensão da infraestrutura para ciclistas e de transporte público, é possível verificar a existência de relação com as altas taxas de deslocamento por transportes ativos, baixas taxas de acidentes. 
Tabela 2 - Estatísticas básicas dos indicadores quantitativos

\begin{tabular}{|c|c|c|c|c|c|}
\hline \multirow{2}{*}{ Tema } & \multirow{2}{*}{ Indicador } & \multicolumn{4}{|c|}{ Estatísticas básicas } \\
\hline & & Média & Máximo & Mínimo & Des. padrão \\
\hline Infraestrutura cicloviária & $\begin{array}{l}\text { Extensão cicloviária }(\mathrm{km}) \\
\text { Densidade cicloviária }\left(\mathrm{km} / \mathrm{km}^{2}\right) \\
\text { Densidade per capita }(\mathrm{km} / 100 \mathrm{mil} \text { hab.) } \\
\text { Viagens feitas por bicicleta }(\%) \\
\text { Número bicicleta compartilhadas/100mil hab. }\end{array}$ & $\begin{array}{r}376,3 \\
2,8 \\
81,4 \\
16,4 \% \\
344,6\end{array}$ & $\begin{array}{r}1.200,0 \\
8,1 \\
233,9 \\
56,0 \% \\
1.618,9\end{array}$ & $\begin{array}{r}133,0 \\
0,2 \\
3,2 \\
0,8 \% \\
0\end{array}$ & $\begin{array}{r}144,0 \\
1,9 \\
50,7 \\
13,8 \% \\
253,2\end{array}$ \\
\hline Infraestrutura ferroviária & $\begin{array}{l}\text { Extensão infraestrutura ferroviária }(\mathrm{km}) \\
\text { Pessoas por km de infraestrutura (hab./km) } \\
\text { Número de estações por } 100 \text { mil habitantes } \\
\text { Número de viagens de trem (viagens } / 100 \text { mil hab.) }\end{array}$ & $\begin{array}{r}93,4 \\
16.138 \\
18 \\
46.115\end{array}$ & $\begin{array}{r}191,0 \\
65.660 \\
64 \\
110.383\end{array}$ & $\begin{array}{r}10,0 \\
2.944 \\
0 \\
0\end{array}$ & $\begin{array}{r}50,7 \\
14.034 \\
15 \\
30.846\end{array}$ \\
\hline Peatonal & $\begin{array}{l}\text { Área de ruas exclusivas para pedestres }\left(\mathrm{km}^{2}\right) \\
\text { Viagens a pé }(\%)^{* * *}\end{array}$ & $\begin{array}{r}0,37 \\
16,5 \%\end{array}$ & $\begin{array}{r}2,00 \\
37,0 \%\end{array}$ & $\begin{array}{r}0,01 \\
5,8 \%\end{array}$ & $\begin{array}{r}0,4 \\
8,4 \%\end{array}$ \\
\hline Infraestrutura de ônibus & Número de ônibus/100 mil hab. & 124,72 & 237,53 & 24,88 & 59,9 \\
\hline Transporte público & Viagens feitas por transporte público (\%) & $21,0 \%$ & $34,0 \%$ & $7,0 \%$ & $7,6 \%$ \\
\hline Frota de veículos & $\begin{array}{l}\text { Número de carros por habitante } \\
\text { Carros compartilhados por } 100 \text { hab. }\end{array}$ & $\begin{array}{r}0,47 \\
65,10\end{array}$ & $\begin{array}{r}0,93 \\
237,53\end{array}$ & $\begin{array}{r}0,11 \\
0\end{array}$ & $\begin{array}{r}0,2 \\
63,5\end{array}$ \\
\hline Carros elétricos & Número de estações de recarga por 100mil hab. & 26,2 & 106,7 & 0,1 & 28,6 \\
\hline Transporte ativo & Viagens transporte ativo (\%) & $51,1 \%$ & $91,0 \%$ & $24,9 \%$ & $18,3 \%$ \\
\hline Acidentes & $\begin{array}{l}\text { Número de óbitos de ciclistas/ } 100 \text { mil hab. } \\
\text { Número de óbitos de pedestres/ } 100 \text { mil hab. }\end{array}$ & $\begin{array}{l}0,45 \\
1,30\end{array}$ & $\begin{array}{l}1,40 \\
5,42\end{array}$ & $\begin{array}{r}0 \\
0,18\end{array}$ & $\begin{array}{l}0,3 \\
0,9\end{array}$ \\
\hline
\end{tabular}

* EUA dados para deslocamentos exclusivos para trabalho; ** Análise não considera Curitiba, devido à ausência de dados. Fonte: os autores.

As condições representadas pelos indicadores avaliados demonstram que governos que investiram em uma matriz de modos de transporte ativos e coletivos contribuíram para a melhoria das condições de qualidade de vida e de mobilidade urbana sustentável que as colocam em posição elevada na comparação com outras cidades, evidenciada nos sistemas de avaliação.

A análise deve considerar, ainda, as nuanças das cidades e dos países analisados, haja vista que os sistemas de avaliação possuem uma limitação de avaliação de cidades ao longo de todo o mundo, sendo a maioria restrita a determinada unidade geográfica, continente ou cidades selecionadas, capitais, etc. Nesse contexto, foi possível observar que, mesmo algumas cidades sendo de referência - por exemplo, Santiago e Curitiba, na América Latina -, pela superação de desafios aplicados a realidades particulares de seus países, elas se encontram muito aquém dos indicadores aqui avaliados de outras cidades, sobretudo de países desenvolvidos, com destaque para a Europa. 
Nesse sentido, um dos pontos favoráveis da utilização de cidades como benchmarking é a possibilidade de estabelecimento de objetivos e metas com base nas melhores práticas. Planejadores urbanos podem tirar lições valiosas desses números, incorporando conceitos e outras dimensões que não econômicas à proposição de soluções para os problemas em centros urbanos brasileiros, permitindo entender como as ações implementadas nos sistemas de mobilidade proporcionam ganhos sociais, econômicos e ambientais aos usuários e cidadãos, contribuindo para a prosperidade de cidades e países.

\section{Medidas de controle institucionais e de planejamento urbano}

Esta análise foi organizada elencando ações de planejamento ou institucionais aplicadas ao sistema de transportes e mobilidade urbana. Estas auxiliam, de forma complementar, a compreender os indicadores alcançados pelas cidades, acima demonstrados. Ademais, medidas de controle são fundamentais para o desenvolvimento integrado de melhorias na mobilidade urbana, sejam elas regulamentações legais, protocolos de design urbano ou mecanismos de monitoramento e geração de dados.

Com relação ao planejamento urbano, de forma geral, as ações mais citadas referem-se à restrição de áreas de circulação de carros em zonas centrais da cidade e à redução da velocidade de circulação de veículos, criando vias para pedestres, para fomentar o uso peatonal e reduzir os impactos negativos de veículos, além de compatibilizar infraestrutura ferroviária nessas zonas (Quadro 4).
Outras ações desenvolvidas referem-se à criação de locais de park+ride (estacionamentos localizados próximos a áreas de transporte público, bicicletas, etc.) que possibilita, aos condutores, estacionar os veículos e seguir trajeto de bicicleta ou acessar transporte público, fomentando o uso de transporte ativo. Ainda, a integração entre modais é muito enfatizada. Como solução para estacionamentos, também foi verificada a possibilidade de criação de vagas subterrâneas para veículos em zonas centrais, com os objetivos de não comprometer a qualidade da estética urbana e ampliar espaços para a circulação de pedestres e ciclistas. A questão da estética urbana é elencada em diversas cidades como fator que influencia diretamente no deslocamento de ciclistas e pedestres, principalmente.

Com relação ao controle do ruído de fontes móveis, a maioria das cidades possui um sistema de monitoramento do ruído associado a mapas temáticos. Entre as estratégias para reduzir esse impacto, também foi enfatizada a criação de rotas específicas para cargas pesadas, utilização de pavimentos menos ruidosos, barreiras e isolamento de construções e a densificação de áreas centrais e adequação acústica de edificações para redução do ruído. Além disso, são citadas normativas relacionadas ao zoneamento de ruído e de legislação específica de controle (federais ou municipais).

No que se refere à poluição atmosférica, as ações adotadas pelos municípios são relacionadas ao monitoramento da concentração de principais poluentes, substituição de frota de transporte público por carros de baixa ou nula emissão (veículos elétricos ou hidrogênio). Destacam-se, ainda, medidas relacionadas ao zoneamento dos níveis de ruído e ao fomento 
do uso de transporte ativo e a existência de taxa de congestionamento em Singapura, cobrada para veículos no centro comercial em horário de pico.

Com relação a banco de dados e estudos específicos para a geração de dados e subsídio a uma gestão mais eficiente do sistema de transportes e mobilidade urbana, observam-se estudos específicos para ciclistas, pedestres, pesquisas de deslocamento, planos diretores por tipos de modais e procedimentos para a coleta de dados.

Em conjunto com as medidas estruturais como infraestrutura de transportes, as medidas institucionais e de gestão são fundamentais para um controle de externalidades do sistema de transportes urbanos, com destaque para a poluição atmosférica e ruído, bem como na aquisição e apresentação de dados de qualidade e de forma contínua, que são determinantes para a composição de planejamento urbano.

Observa-se que muitas das decisões inadequadas de planejamento urbano nas cidades brasileiras e avaliações de soluções alternativas são processos que passam ao largo de estudo, uma vez que não há dados suficientes para a comprovação de melhores alternativas a longo prazo. A tomada de decisão acerca de ações estruturais e não estruturais compatíveis com as necessidades da população considera, quase exclusivamente, condições financeiras de investimentos, não sendo avaliado o custo público do atual modelo de transportes implementado, para que seja comparado com soluções alternativas, além de benefícios indiretos, custos sociais e ambientais a longo prazo.

Isso também causa uma falha de julgamento por parte de tomadores de decisões, uma vez que os benefícios econômicos de um modelo eficiente de transportes e mobilidade urbana serão concretizados em longo prazo, como ressaltam Newman (2014) e Maciulis, Vasiliauskas e Jakubauskas (2009), gerando um dinamismo econômico na cidade, atraindo investimentos, tecnologia de ponta e referência no setor econômico pela logística proporcionada, maximizando investimentos, eficiência e competitividade das cidade, região e da nação como um todo.

\section{Conclusão}

A utilização de sistemas de avaliação em nível mundial permitiu obter uma seleção precisa dos indicadores e temas utilizados para avaliar condições de mobilidade urbana enquanto eixo de promoção de qualidade de vida, qualidade ambiental urbana e sustentabilidade. Os indicadores permitiram conhecer 0 desempenho das cidades em função das suas infraestruturas implementadas, com destaque para o transporte ativo, além de aspectos institucionais e de gestão de externalidades.

Mediante isso, as cidades mais bem-classificadas nos sistemas de avaliação foram comparadas por meio dos indicadores selecionados, permitindo identificar quais as ações que cidades com altos níveis de desempenho de transportes e mobilidade urbana realizam, gerando um instrumento, para governantes e técnicos, das ações de melhoria que podem orientar políticas nas cidades brasileiras.

Soma-se a isso o fato de que a maioria das ações, principalmente de infraestrutura, é observada em várias cidades do estudo de caso. Isso demonstra que há metodologias consagradas para que se alcancem elevados índices 


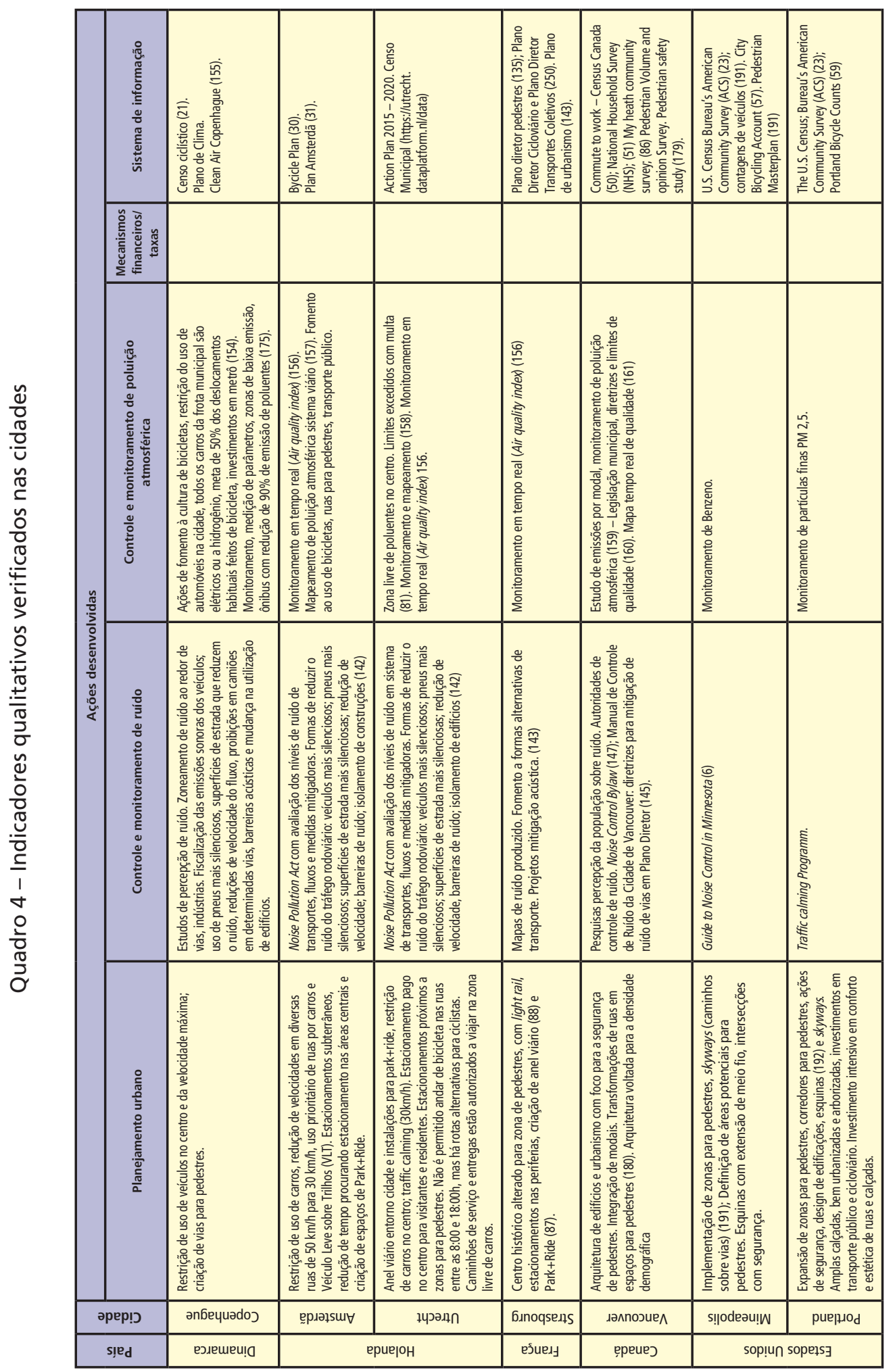




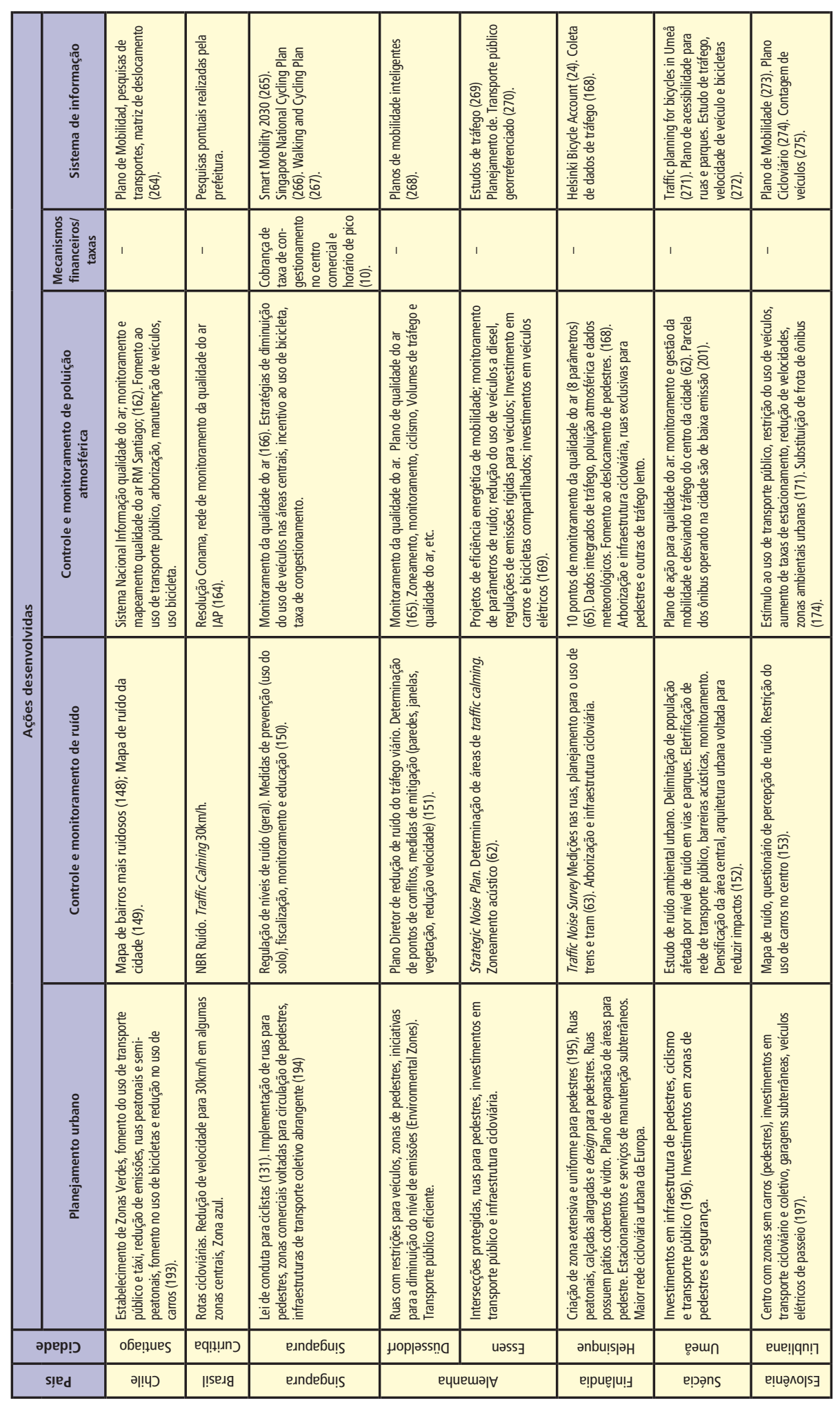

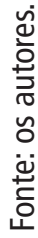


de desempenho da mobilidade urbana, não necessariamente demandando soluções inovadoras, haja vista que a maioria dos desafios de mobilidade urbana foi ou está sendo superada pelas cidades estudadas, por exemplo. Não obstante a isso, soluções de problemas de mobilidade urbana demandam conhecimentos profundos, diagnósticos apurados, incluindo condições demográficas, socioeconômicas e estudos técnicos que sejam adequados às condições socioeconômicas e com o dimensionamento das ações compatível com os anseios da população brasileira.

Apesar de todas as cidades analisadas possuírem pontos de destaque no que se refere a ações de mobilidade urbana sustentável, os indicadores demonstraram o melhor desempenho das cidades europeias. Por exemplo, Copenhague e Amsterdã possuem taxas de deslocamento por transporte ativo que atingem 90\%; Helsinque, Umea e Essen, com índices de acidentes fatais praticamente nulos; Santiago e Singapura com baixas taxas per capita de carros particulares, Helsinque e Estrasburgo com taxas elevadas de infraestrutura peatonal.

Essa comparação demonstrou uma robustez no sentido de comunicar aspectos estruturais e não estruturais que foram fundamentais para que as cidades atingissem elevados índices dentro dos objetivos propostos por seus sistemas de avaliação. Os indicadores demonstraram que as cidades comparadas possuem diversas ações em comum, com destaque para o incentivo ao uso de transporte ativo (peatonal e cicloviária), associadas a amplas infraestruturas de transporte coletivo ferroviário e rodoviário, ofertados de forma eficiente e bem-estabelecidos dentro das necessidades da população, investimentos em segurança nos deslocamentos, além de iniciativas relacionadas ao uso compartilhado de modais. Como consequência, altas taxas de uso pela população são observadas, proporcionando uma redução de impactos ambientais e a melhoria nos indicadores de qualidade de vida e ambiental.

Conclui-se que cidades que enfrentam severos problemas com a questão dos transportes, como é o caso no Brasil, podem aprender com outras, com base nas ações bem-sucedidas e consagradas dessas cidades, adequando-as à realidade de cada local. Dessa forma, pesquisas relacionadas podem exercer influência sobre tomadores de decisão, desenvolvimento de estratégias específicas, além de gerar espírito de competição entre cidades por melhores colocações. Dessa forma, para trabalhos futuros, recomendam-se o aprofundamento dos indicadores selecionados e sua correlação com aspectos de qualidade de vida, ambiental e econômica das cidades, bem como o impacto da melhoria das condições de mobilidade na economia, no meio ambiente e na qualidade de vida e a validação para outros estudos de caso. 


\section{[I] https://orcid.org/0000-0001-6305-088X}

Universidade do Vale do Itajaí, Escola do Mar, Ciência e Tecnologia. Itajaí, SC/ Brasil. tischer@edu.univali.br

\section{[II] https://orcid.org/0000-0003-0437-4205}

Universidade do Vale do Itajaí, Escola do Mar, Ciência e Tecnologia. Itajaí, SC/ Brasil. mpolette@univali.br

\section{Referências}

ANDRADE, M. F. et al. (2017). Air quality in the megacity of São Paulo: evolution over the last 30 years and future perspectives. Atmospheric Environment, n. 159, pp. 66-82.

CARR, L. J. et al. (2010). Walk score as a global estimate of neighborhood walkability. American Journal of Preventive Medicine, v. 39, n. 5, pp. 460-463.

CDC - Copenhagenize Design Company (2017). The criteria for the Copenhagenize Index. Disponível em: <http://copenhagenizeindex.eu/criteria.html>. Acesso em: 2 maio 2017.

CNM - Confederação Nacional de Municípios (2016). Mobilidade urbana municipal: a gestão do trânsito e o plano de mobilidade - Coletânea Gestão Pública Municipal: Gestão 2017-2020. Brasília, CNM.

DEY, S.; CAULFIELD, B. e GHOSH, B. (2018). Potential health and economic benefits of banning diesel traffic in Dublin, Ireland. Journal of Transport \& Health, n. 10, pp. 156-166.

DUNCAN, D. T. et al. (2011). Validation of walk score for estimating neighborhood walkability: an analysis of four US metropolitan areas Int. J. Environ. Res. Public Health, v. 8, pp. 4160-4179.

EC - European Commission (2017). European Green Capital Award 2020. Guidance Note.

GIFFINGER, R. e GUDRUN, H. (2010). Smart cities ranking: an effective instrument for the positioning of cities? ACE: Architecture, City and Environment, Ano IV, n. 12, pp. 7-25.

GUDMUNDSSON, H. (2000). Indicators and performance measures for transportation, environment and sustainability in North America. Report from a German Marshall Fund Fellowship. Denmark, National Environmental Research Institute.

HAMMOND, A. et al. (2005). Environmental Indicators: a systematic approach to measuring and reporting on environmental policy performance in the context of sustainable development. World Resources Institute. Washington.

IBGE - Instituto Brasileiro de Geografia e Estatística (2010). Censo demográfico IBGE. Rio de Janeiro. (2016). Síntese de indicadores sociais: uma análise das condições de vida da população brasileira: 2016/IBGE, Coordenação de População e Indicadores Sociais. Rio de Janeiro, IBGE.

KOZARYN, A. O. (2013). City life: rankings (livability) versus perceptions (satisfaction). Soc. Indic. Res., n. 110, pp. $433-451$. 
LLACUNA, M. L. M. et al. (2014). Lessons in urban monitoring taken from sustainable and livable cities to better address the Smart Cities initiative. Technological Forecasting \& Social Change, n. 90, pp. 611-622.

LINDAU, L. A.; PETZHOLD, G. S.; SILVA, C. A. M. e FACCHINI, D. (2013). BRT e Corredores prioritários para ônibus: panorama no Continente Americano. In: XXVII ANPET - CONGRESSO DE PESQUISA E ENSINO EM TRANSPORTES. Journal. Belém do Pará, 4-8, nov.

MAČIULIS, A.; VASILIAUSKAS, A. V. e JAKUBAUSKAS, G. (2009). The impact of transport on the competitiveness of national economy. Transport, v. 24, n. 2, pp. 93-99.

MIRANDA, H. F.e SILVA, A. N. R. (2012). Benchmarking sustainable urban mobility: the case of Curitiba, Brazil. Transport Policy, 21, pp. 141-151.

MEIJERING, J. V.; KERN, K. e TOBI, H. (2014). Identifying the methodological characteristics of European green city rankings. Ecological Indicators, n. 43, pp. 132-142.

MERCER (2015). Quality of living Reports. Disponível em: < https://mobilityexchange.mercer.com/ quality-of-living-reports>. Acesso em: 25 jun 2017.

MOEINADDINI, M. et al. (2015). An urban mobility index for evaluating and reducing private motorized trips. Measurement, n. 63, pp. 30-40.

MONTGOMERY, C. (2017). Happy city: transforming our lives through urban design. Nova York, Farrar Straus Giroux.

MORAIS, P. et al. (2013). Quality of life experienced by human capital: an assessment of European Cities Paulo. Soc. Indic. Res., n. 110, pp. 187-206.

NEWMAN, P. (2014). Sustainability and global cities. Australian Planner, v. 41, n. 4.

NTU - Associação Nacional de Empresas de Transportes Urbanos (2017). Pesquisa mobilidade da população urbana 2017. Confederação Nacional do Transporte - CNT, Associação Nacional das Empresas de Transportes Urbanos - NTU. Brasília, CNT e NTU.

OECD - Organisation for Economic Cooperation and Development (2018). Urban population by city size. OECD iLibrary.Disponível em: < https://data.oecd.org/popregion/urban-population-by-citysize.htm>. Acesso em: 21 jul 2018.

PORTUGAL, L. S. (2017). Transporte, mobilidade e desenvolvimento urbano. São Paulo, Elsevier.

PUCHER, J. e BUEHLER, R. (2008). Cycling for everyone: lessons from Europe. Transportation Research Record. Washington, n. 2074, pp. 58-65.

RENNER, M. e GARDNER, G. (2010). Global competitiveness in the rail and transit industry. Washington, Worldwatch Institute.

RUBIN, B. e LEITÃO, S. (2013). O Plano de Mobilidade Urbana e o futuro das cidades. Estudos Avançados, v. 27, n. 79

SADIK-KHAN, J. e SOLOMONOW, S. (2017). Streetfight: Handbook for urban revolution. Nova York, Penguin Books.

SCHÖNERT, M. (2003). Städteranking und Imagebildung: Die 20 grössten Städte in Nachrichten- und Wirtschaftsmagazinen. BAW Monatsbericht, n. 2, pp. 1-8. 
SILVA, A. N. R. et al. (2010). Development and application of I SUM - an index of sustainable urban mobility. Transportation Research Board Annual Meeting.

UITP - International Organisation for Public Transport (2014). The future of urban mobility 2.0.

WALK SCORE (2017). Cities \& neighborhoods. Disponível em: <https://www.walkscore.com/cities-andneighborhoods/>. Acesso em: 12 dez 2017.

ZAYED, M. A. (2016). Towards an index of city readiness for cycling. International Journal of Transportation Science and Technology, v. 5, n. 3, pp. 210-225.

Texto recebido em 15/ago/2018

Texto aprovado em 28/nov/2018 
